\title{
Apropriação dos custos indiretos de fabricação em indústrias cerâmicas do sul catarinense
}

Edilson Citadin Rabelo Mestrado em andamento em Ciências Contábeis pela Universidade Federal de Santa Catarina - UFSC UFSC - Campus Universitário. Trindade. Florianópolis/SC E-mail: edilson.rabelo@gmail.com

Altair Borgert
Doutorado em Engenharia de Produção pela Universidade Federal de Santa Catarina
UFSC - Campus Universitário. Trindade. Florianópolis/SC
E-mail: borgert@cse.ufsc.br

Cristiano Salvador Calixto de Medeiros

Mestrado em Contabilidade pela Universidade Federal de Santa Catarina - UFSC Faculdades Borges de Mendonça. Rua Santos Dumont, 104. Centro. Florianópolis/SC E-mail: criscalixtomedeiros@yahoo.com.br

\section{RESUMO}

Este artigo apresenta um estudo referente ao comportamento dos custos em indústrias cerâmicas e argumenta sobre a utilização dos critérios para alocação dos custos indiretos de produção. Os dados pesquisados foram coletados em um período de doze meses, no ano de 2008, e extraídos diretamente das planilhas de custos de três indústrias cerâmicas da região sul do estado de Santa Catarina. Trata-se, portanto, de uma pesquisa de caráter descritivo e exploratório, com abordagem qualitativa e quantitativa, cujo objetivo é analisar, estatisticamente, a aderência dos critérios utilizados em indústrias cerâmicas para rateio dos custos indiretos de produção. Para tal propósito, foram testados dois critérios de rateio: o volume produzido $\mathrm{em}^{2}$ e 0 consumo de massa em toneladas, como variáveis independentes, e, dois itens de custos indiretos: o consumo de gás em $\mathrm{m}^{3}$ e o valor da mão-de-obra indireta em $R \$$, como variáveis dependentes. Em relação à "mão-de-obra indireta", com a utilização dos critérios "volume produzido" e "consumo de massa", as análises apontam índices em torno de $41 \%$, considerada como uma "correlação positiva moderada". Já, em relação ao "consumo de gás", o grau de correlação encontrado atingiu uma média de $73 \%$, considerada "forte correlação positiva". Como resultado final, conclui-se que as empresas em questão necessitam rever seus critérios de rateios, além de demonstrar que não existe um comportamento uniforme para os três casos estudados.

Palavras-chave: Correlação e regressão. Critérios de rateio. Custos indiretos.

Indirect Costs of Ceramic Manufacturing Industries of the South of Santa Catarina 


\section{ABSTRACT}

This paper presents not only a study related to the ceramic cost behavior in ceramic industries but also an argument about the use of the criteria for the production indirect costs allocation. The researched data were collected into a twelve month period, in 2008, and were also directly taken out from costs spreadsheets of three ceramic industries of the south of Santa Catarina. It is, therefore, an exploratory and descriptive research bringing some qualitative and quantitative approaches, whose goal is to statistically analyze, the adherence of the criteria used in ceramic industries for the apportionment of indirect costs of production. For this purpose, two criteria of apportionment were tested: the volume produced in $\mathrm{m}^{2}$ and mass consumption in tons, as independent variables, and also two items of indirect costs: the gas consumption in $\mathrm{m}^{3}$ and the value of the indirect labor in $\mathrm{R} \$$, as independent variables. Regarding the indirect labor, using the criteria "volume produced" and "mass consumption", the analysis indicate rates around $41 \%$, It is considered to be a "moderate positive correlation". On the other hand, regarding the "gas consumption" the correlating degree found has reached an average of $73 \%$, which is considered "strong positive correlation". To sum up, it has been understood that the companies still need to revise their criteria of apportionment, furthermore showing that there isn't a uniform behavior for the three cases studied.

Key words: Correlation and regression. Apportionment Criteria. Indirect costs.

\section{INTRODUÇÃO}

No ambiente competitivo em que as organizações estão inseridas, surge à necessidade de as empresas conhecerem os seus custos com o objetivo de gerenciar a sua capacidade de produção e gerar riqueza, para conduzir seus negócios da forma mais abrangente possível, bem como, encontrar uma maneira de estar à frente da concorrência. Logo, é importante produzir informações qualificadas no que diz respeito à apropriação dos seus gastos, principalmente os custos indiretos de fabricação, no sentido de identificar o melhor critério de rateio a ser utilizado, uma vez que a grande dificuldade, no mundo contemporâneo, é compreender o comportamento dos custos indiretos, o que pode prejudicar e distorcer os resultados das entidades.

No processo industrial, os custos diretos são alocados diretamente aos produtos, ficando mais complexo o processo, na medida em que aparecem os custos de difícil mensuração, determinando quais custos indiretos precisam ser efetivamente alocados aos produtos fabricados por meio de algum esquema matemático denominado rateio. 
Tanto na indústria quanto no comércio, os gestores querem garantir a maximização dos resultados das corporações com os recursos disponíveis, garantindo aos investidores a rentabilidade sobre o capital aplicado. Tendo em vista essa necessidade, torna-se imprescindível a evolução e o acompanhamento constante da Contabilidade de Custos, a fim de proporcionar aos seus usuários internos - gestores informações atualizadas procurando meios de minimizar os custos e mensurá-los da melhor forma possível para atender as mais variadas necessidades do negócio. Portanto, as gestões empresariais, juntamente com a contabilidade de custos, buscam técnicas mais apropriadas para auxiliar e contribuir na tomada de decisões.

Atkinson et al. (2000, p. 183), sobre a importância do comportamento dos custos, afirmam que

os custos estão relacionados com os direcionadores de custos de múltiplos níveis [...]. Mas os administradores estão sempre interessados em como os custos mudam, como uma mudança no nível de um importante direcionador de custo, o volume da produção, porque muitas decisões de marketing, produção e investimento afetam o volume de produção. Para suprir essa informação para administradores, tradicionalmente, as empresas classificam os custos entre custos fixos e custos variáveis, baseados em seu comportamento em resposta às mudanças no volume de produção.

Durante pesquisas realizadas junto às indústrias cerâmicas, observou-se uma constante preocupação com os tratamentos efetuados na distribuição dos custos indiretos e o seu comportamento, no sentido de parametrizações de critérios de rateios existentes, pois os custos fixos se tornaram relevantes, através da redução da mão-deobra substituída por novas tecnologias. Sob a luz dessa afirmação, tem-se como objetivo, nesta pesquisa, analisar o comportamento dos custos indiretos de fabricação e seu correlacionamento estatístico na utilização de diferentes critérios de rateios adotados pelas empresas cerâmicas da região sul de Santa Catarina.

Esta pesquisa iniciou no Sindicato das Indústrias de Cerâmicas do Sul do estado de Santa Catarina (Sindiceram) que, por meio de seu estatuto, determina que a base territorial para o Sindicato abranja os municípios de Criciúma, Cocal do Sul, Urussanga, 
Morro da Fumaça, Imbituba, Içara, Sangão, Maracajá, Forquilhinha, Nova Veneza, Siderópolis, Treviso, Orleans, Lauro Müller, São Ludgero, Armazém, Pedras Grandes e Rio Fortuna, todos no Sul do Estado de Santa Catarina, onde se concentra o maior número de cerâmicas.

Com base nos dados do Sindiceram, identificaram-se doze indústrias registradas, contudo, em função da semelhança, porte e acessibilidade, o estudo foi direcionado a três destas indústrias cerâmicas. Em contato com os dirigentes das mesmas, estes prontamente concordaram em fornecer dados para o estudo, e constatou-se que devido as suas particularidades, as empresas analisadas tendem a utilizar as mesmas técnicas para gerenciamento dos custos de produção, possivelmente em decorrência da utilização dos mesmos sistemas de controles específicos para o setor cerâmico. Como as empresas em questão solicitaram sigilo sobre as suas identidades, reserva-se, neste artigo, o direito de ocultar o nome das referidas indústrias, que são designadas como "Alfa", "Beta" e "Gama".

Estas três empresas concorrem no mercado e entendem a necessidade de competitividade entre elas, utilizando padrões, tecnologias e critérios significativamente semelhantes no tratamento de seus custos indiretos.

A correlação e a regressão, importantes técnicas, estatísticas foram empregadas como instrumento para evidenciar se há uma boa aderência, ou não, nos critérios de rateio utilizados por estas indústrias cerâmicas, no tratamento de seus custos indiretos de produção. Os custos indiretos são calculados adotando-se estes instrumentos da estatística para a análise dos critérios selecionados (Massa e Produção), em comparação com os critérios de rateio utilizados para os custos indiretos.

Identificar, portanto, possíveis direcionadores - neste estudo como sinônimos de critérios de rateio - para os custos indiretos, procurando aproximação coerente para o comportamento dos custos neste setor cerâmico, também é uma das preocupações deste estudo, além de contribuir para um maior grau de eficiência às referidas empresas. Por serem complexos e exigirem precisão, os cálculos de correlação e regressão são elaborados em planilhas, no programa Excel, com o uso de estatística para a análise dos custos indiretos de produção. 
No passado, os custos destacados como relevantes eram, basicamente, a mãode-obra e a matéria-prima, e o restante era dividido proporcionalmente com base em algum critério, não afetando o resultado final de forma preocupante. Atualmente, as empresas cerâmicas Alfa, Beta e Gama estão se modernizando, tomando novas decisões, o que gera uma preocupação nas alocações de custos, já que um maior grau de adequação técnica é exigido.

Diante do exposto, questiona-se: como se comportam os custos indiretos de produção e os critérios de rateios utilizados em indústrias cerâmicas do sul do estado de Santa Catarina?

\section{ASPECTOS METODOLÓGICOS}

Para responder a questão central deste estudo, foram utilizados dados referentes ao período de janeiro a dezembro do ano 2008, de três empresas industriais cadastradas no Sindiceram, todas do ramo cerâmico. A natureza da pesquisa é aplicada, utilizando-se de abordagem quantitativa e qualitativa. Os objetivos são descritivos e exploratórios, sendo que, os procedimentos técnicos baseiam-se em análise estatística de correlação e regressão.

A coleta dos dados foi obtida diretamente de planilhas de custos informadas pelas três indústrias objetos do estudo, já qualificadas anteriormente.

Foram realizadas pesquisas em artigos e livros que tratam sobre custos indiretos no campo da Contabilidade e da Administração, seus comportamentos e alocações, bem como os critérios de rateios e absorção que são empregados nas indústrias cerâmicas em estudo. Buscou-se, ainda, nas mesmas fontes, orientações sobre correlação e regressão para obter os esclarecimentos necessários sobre os temas abordados neste artigo.

Com o uso da estatística as informações tornaram-se concisas, específicas e eficazes, e através de análises forneceram subsídios imprescindíveis. Nesta visão, os métodos quantitativos foram instrumentos importantes para definir e avaliar qual das três indústrias cerâmicas apresenta uma boa aderência dos seus custos fixos em 
relação aos seus custos variáveis, e principalmente, identificar seus pontos fracos.

Nas indústrias cerâmicas Alfa, Beta e Gama levantaram-se os custos indiretos: gás em $\mathrm{m}^{3}$ e MOI (Mão-de-obra indireta) em valores monetários, além de dois critérios de rateio: volume produzido de cerâmica em $\mathrm{m}^{2}$ e consumo de massa em toneladas. Assim, correlacionou-se, individualmente, cada custo indireto com cada critério de rateio, para identificar qual dos três casos estudados apresenta o maior índice de correlação, considerando-se, neste sentido, o critério mais relevante para os custos indiretos.

\section{REFERENCIAL TEÓRICO}

\subsection{Custos e métodos de custeio}

Conforme Martins (2008, p.25), um custo representa um "gasto relativo à bem ou serviço utilizado na produção de outros bens ou serviços". Custos estes, que apresentam grande influência para a formação de preço.

Com o ambiente competitivo, tanto às empresas de serviços quanto às empresas industriais tornaram-se exigentes e buscam novos desafios. A procura por informações gerenciais contábeis diferentes e melhores, força as empresas a controlarem seus custos, para que resulte em um menor preço final, tornando-as mais competitivas e lucrativas em relação ao seu produto. Quando um sistema de custos é implantado, deseja-se um sistema que funcione e traga benefícios à empresa. Assim, este é desenvolvido sob medida, para determinada organização, contando com 0 planejamento e controle da administração.

A modernização na parte operacional das indústrias conduziu-as à tentativa de encontrar o melhor tratamento dos custos de produção. Com o passar dos anos, destacaram-se os métodos de Custeio por Absorção; Custeio Variável e Custeio Baseado em Atividades.

Durante a pesquisa, verificou-se que o método mais utilizado pelas empresas Alfa, Beta e Gama é o custeio por absorção. 


\subsection{Custeio por absorção}

O custeio por absorção tem a função de apropriar todos os custos de fabricação, administração e vendas dos bens e serviços produzidos, sejam eles diretos ou indiretos.

Segundo Viceconti e Neves (2000, p.33), custeio por absorção:

é um processo de apuração de custos, cujo objetivo é ratear todos os seus elementos (fixos ou variáveis) em cada fase da produção. Logo, um custo é absorvido quando for atribuído a um produto ou unidade de produção. Assim, cada unidade ou produto receberá sua parcela no custo até que o valor aplicado seja totalmente absorvido pelo Custo dos Produtos Vendidos ou pelos Estoques Finais.

Quando se sabe que Custeio significa apropriação de custos, são alocados todos os custos de produção aos produtos fabricados, onde todos os custos fixos e variáveis, conhecidos como de fabricação, são absorvidos pelo estoque.

Para Martins (2008, p.37), o "custeio por absorção é o método derivado da aplicação dos Princípios de Contabilidade Geralmente Aceitos". O autor comenta, ainda, que o custeio por absorção "consiste na apropriação de todos os custos de produção aos bens elaborados, e só os de produção; todos os gastos relativos ao esforço de fabricação são distribuídos para todos os produtos feitos. "

A contabilidade de custos tem o custeio por absorção como o principal critério para conseguir o custo total, tanto os diretos quanto os indiretos, para cada objeto de custeio. Leone (2000, p.26) afirma que "esse custo total se destina, entre outros fins, a determinar a rentabilidade de cada atividade, a avaliar os elementos que compõem o patrimônio e a compor uma informação significativa no auxílio à decisão de estabelecer os preços de venda dos produtos ou dos serviços."

Quando se fala em custeio por absorção, vem logo à mente a palavra rateio, contudo os registros das despesas financeiras são tratados como despesa na contabilidade atual, juntamente com todas as despesas da empresa e não como custos de produção. Legalmente, ainda não é possível este processo em nosso país, mas para fins gerenciais ele se torna importante e útil. Martins (2008, p.39), cita "[...] quando se usa Custos para finalidades gerencias de decisão e controle, os tratamentos podem ser 
totalmente diferenciados."

É necessário que uma organização se preocupe com a informação gerencial contábil, pois esta auxilia nas atividades decisórias e de resoluções de problemas, obtendo um gerenciamento da empresa de maneira geral, contribuindo para a tomada de decisões.

Para sanar a deficiência de seus controles, as empresas criaram os processos de departamentalização, objetivando aumentar a credibilidade na alocação dos custos aos produtos. Os operadores desenvolveram centros de custos, conhecendo-os e tornando a alocação aos produtos de forma que transpareçam a realidade. Em síntese, este método tem recebido muitas críticas na literatura, no que se refere à arbitrariedade que existe na distribuição dos custos de fabricação aos produtos, gerando dúvidas em suas informações, principalmente de ordem gerencial.

\subsection{Correlação e regressão}

Na correlação, o principal objetivo é analisar uma coleção de dados amostrais emparelhados e determinar se há relação entre duas variáveis. Em estatística, esta relação se refere à correlação. Nas relações lineares quando colocadas em gráficos, os pontos se aproximam do padrão de uma reta. Triola (2005, p.381) define assim a correlação: "existe uma correlação entre duas variáveis quando uma delas está relacionada com a outra de alguma maneira."

É proposto que a correlação deva atingir um coeficiente $(r)$ e que jamais poderá ser superior a 1 ou menor do que -1 . E se for próximo de zero indica que as duas variáveis encontradas não estão relacionadas. Já a correlação negativa (-1) demonstra que as duas variáveis têm o comportamento seguindo a direção oposta. Uma correlação positiva $(+1)$ demonstra que as duas variáveis estão na mesma direção, ou seja, a relação entre elas é forte.

Stevenson (1981), afirma que duas variáveis, $X$ e $Y$, quando caminham num mesmo sentido são positivamente correlacionadas, e explica que, elementos com valores pequenos de $X$ provavelmente geram valores pequenos de $\mathrm{Y}$, e elementos com valores grandes de $X$, tendem a ter valores grandes de $Y$. E quando são negativamente 
correlacionados caminham em sentidos opostos, ou seja, elementos com valores pequenos de $\mathrm{X}$ tendem a gerar valores grandes de $\mathrm{Y}$ e elementos com valores grandes de $\mathrm{X}$ tendem a ter valores pequenos de $\mathrm{Y}$.

$\mathrm{Na}$ análise de dados em pares, tem-se o objetivo de determinar se há, ou não, uma correlação entre duas variáveis, usando-se gráficos e equações que representam a relação. A reta demonstrada no gráfico é conhecida como reta de regressão, e a equação é chamada de equação de regressão. A definição de regressão, segundo Bisquerra (2004, p.149), "[...] consiste em aproximar uma linha reta de uma nuvem de pontos de um diagrama de dispersão, ou seja, representar mediante uma reta a nuvem de pontos. Esta reta deve sintetizar e representar a nuvem de pontos e pode ser utilizada na predição de valores de uma variável em função de outra. "

Segundo Stevenson (1981, p.341), "a correlação mede a força, ou grau, de relacionamento entre duas variáveis, a regressão dá uma equação que descreve o relacionamento em termos matemáticos". Quando se procura analisar o comportamento de $\mathrm{X}$ e $\mathrm{Y}$ usando-se de meios estatísticos, ou seja, análise de correlação e regressão tem-se a finalidade de identificar através de critérios de rateios de apropriação dos custos indiretos, qual o melhor método a ser adotado.

Tendo em vista que o objetivo desta pesquisa é elaborar a correlação e regressão, considera-se a escala para a determinação da intensidade e a direção da correlação entre as variáveis X e Y, apresentada em Levin (2004), conforme Tabela 1. 
Tabela 1 - Interpretação da correlação

\begin{tabular}{|c|c|}
\hline Correlação & Interpretação \\
\hline$-1,00$ & Correlação negativa perfeita \\
\hline$-0,60$ & Forte correlação negativa \\
\hline$-0,30$ & Correlação negativa moderada \\
\hline$-0,10$ & Fraca correlação negativa \\
\hline 0,00 & Não há correlação \\
\hline$+0,10$ & Fraca correlação positiva \\
\hline$+0,30$ & Correlação positiva moderada \\
\hline$+0,60$ & Forte correlação positiva \\
\hline$+1,00$ & Correlação positiva perfeita \\
\hline
\end{tabular}

Fonte: Levin (2004, p.334).

Compreende-se, até o momento, que na análise de correlação e regressão, há o interesse de saber se duas ou mais variáveis estão relacionadas, buscando nesta análise um número que resuma o grau de relacionamento entre duas variáveis.

\section{ANÁLISE DOS DADOS}

Muitas empresas têm dificuldade em apontar a parcela do custo indireto de produção que pertence a este ou aquele produto, ou ainda, a qual setor. Os dados e exemplos deste estudo tentam demonstrar como podem ser analisados os coeficientes de correlação e regressão, ajudando assim, na escolha dos melhores direcionadores.

O trabalho em questão foi elaborado em três indústrias cerâmicas do sul do estado de Santa Catarina, as quais utilizam o rateio dos custos indiretos de fabricação através do consumo da massa em toneladas. Os gestores de custos explicitam que anteriormente o método de rateio era realizado através do volume produzido $\mathrm{em} \mathrm{m}^{2}, 0$ que direcionou a necessidade de elaborar análise estatística pelo método de correlação e regressão. Não faz parte do escopo desse trabalho alterar qualquer procedimento utilizado pelas indústrias cerâmicas analisadas, mas, supostamente, contribuir com uma nova metodologia de rateio dos custos indiretos.

Quando analisados os coeficientes positivos de correlação, segundo Levin (2004), verifica-se que estes podem ser considerados como apresentando correlação: 
fraca, moderada, forte e perfeita. Desta maneira, o critério a ser usado no rateio da distribuição dos custos indiretos, é aquele que determinar o coeficiente no mínimo superior a $0,50(50 \%)$, e se por ventura, nesta análise apresentar mais percentuais acima de $50 \%$, deverá ser escolhido o maior coeficiente.

Quanto mais próximo de 1,00 estiver o grau de associação em qualquer direção, ou seja, 1,00 ou -1,00, maior será a intensidade da correlação. Como argumenta Levin (2004, p.335) "e como a intensidade de uma correlação independe de sua direção, podemos afirmar que, - 0,10 e + 0,10 indicam igual intensidade (fraca, em ambos os casos) e que $-0,80$ e + 0,80 têm igual intensidade (muito forte, em ambos os casos) ".

É relevante apontar neste momento, que os cálculos para chegar aos resultados de correlação e regressão não são aqui demonstrados, pois o objetivo deste estudo é analisar os coeficientes encontrados e escolher o melhor critério de rateio dos custos indiretos para cada item de custo.

A seguir, nas tabelas de $n^{\circ} 2$ a 4 , demonstram-se os valores das planilhas gerenciais disponibilizadas pelas indústrias cerâmicas. Conforme já abordado anteriormente, são apresentados dois itens de custos indiretos de produção (gás em m³ e mão-de-obra indireta em $R \$$ ) e dois critérios de rateio (volume produzido em $\mathrm{m}^{2} \mathrm{e}$ consumo de massa em toneladas), dados estes referentes ao período de janeiro a dezembro do ano de 2008. Os coeficientes calculados são estudados individualmente, e feita a correlação e regressão de cada critério em relação a cada custo indireto, conforme tabelas 2,3 e 4 . 
Tabela 2 - Custos indiretos e critérios de rateio - Alfa

\begin{tabular}{|c|c|c|c|c|}
\hline \multirow{2}{*}{ MÊS } & \multicolumn{2}{|c|}{ ITENS DE CUSTOS INDIRETOS } & \multicolumn{2}{c|}{ CRITÉRIO } \\
\cline { 2 - 5 } & $\begin{array}{c}\text { Gás Natural } \\
\text { Mil M }^{\mathbf{3}}\end{array}$ & $\begin{array}{c}\text { MOI } \\
\text { R\$ }\end{array}$ & $\begin{array}{c}\text { Vol. } \\
\text { Produzido } \mathbf{M}^{2}\end{array}$ & $\begin{array}{c}\text { Consumo } \\
\text { Massa } \\
\text { Tonelada }\end{array}$ \\
\hline 1 & 933 & 314.303 & 626.592 & 11.181 \\
\hline 2 & 887 & 334.222 & 568.854 & 10.028 \\
\hline 3 & 946 & 372.359 & 606.450 & 10.781 \\
\hline 4 & 905 & 339.613 & 516.843 & 9.815 \\
\hline 5 & 962 & 374.459 & 561.878 & 10.219 \\
\hline 6 & 962 & 336.058 & 510.020 & 9.616 \\
\hline 7 & 907 & 359.904 & 498.162 & 9.848 \\
\hline 8 & 893 & 364.696 & 481.672 & 9.570 \\
\hline 9 & 893 & 390.662 & 462.910 & 9.006 \\
\hline 10 & 889 & 313.210 & 465.613 & 9.280 \\
\hline 11 & 668 & 295.373 & 363.545 & 7.280 \\
\hline 12 & 668 & 302.972 & 453.245 & 8.772 \\
\hline
\end{tabular}

Fonte: Dados da pesquisa

Tabela 3 - Custos indiretos e critérios de rateio - Beta

\begin{tabular}{|c|c|c|c|c|}
\hline \multirow{2}{*}{ MÊS } & \multicolumn{2}{|c|}{ ITENS DE CUSTOS INDIRETOS } & \multicolumn{2}{c|}{ CRITÉRIO } \\
\cline { 2 - 5 } & $\begin{array}{c}\text { Gás Natural } \\
\text { Mil M }^{\mathbf{3}}\end{array}$ & $\begin{array}{c}\text { MOI } \\
\text { R\$ }\end{array}$ & $\begin{array}{c}\text { Vol. } \\
\text { Produzido M }\end{array}$ & $\begin{array}{c}\text { Consumo } \\
\text { Massa } \\
\text { Tonelada }\end{array}$ \\
\hline 1 & 4.491 & 523.000 & 2.673 .000 & 56.525 \\
\hline 2 & 4.449 & 592.000 & 2.500 .000 & 51.717 \\
\hline 3 & 4.574 & 603.000 & 2.453 .000 & 50.764 \\
\hline 4 & 4.672 & 626.000 & 2.557 .000 & 54.648 \\
\hline 5 & 4.473 & 619.000 & 2.788 .000 & 63.096 \\
\hline 6 & 4.812 & 607.000 & 2.829 .000 & 71.787 \\
\hline 7 & 4.850 & 619.000 & 2.748 .000 & 59.906 \\
\hline 8 & 5.043 & 618.000 & 2.911 .000 & 62.054 \\
\hline 9 & 5.393 & 639.000 & 2.911 .000 & 63.533 \\
\hline 10 & 5.605 & 650.000 & 2.977 .000 & 64.867 \\
\hline 11 & 4.513 & 648.000 & 2.615 .000 & 56.099 \\
\hline 12 & 4.250 & 615.000 & 2.316 .000 & 48.913 \\
\hline
\end{tabular}

Fonte: Dados da pesquisa 
Tabela 4 - Custos indiretos e critérios de rateio Gama

\begin{tabular}{|c|c|c|c|c|}
\hline \multirow{2}{*}{ MÊS } & \multicolumn{2}{|c|}{ ITENS DE CUSTOS INDIRETOS } & \multicolumn{2}{c|}{ CRITÉRIO } \\
\cline { 2 - 5 } & $\begin{array}{c}\text { Gás Natural } \\
\text { Mil M }^{\mathbf{3}}\end{array}$ & $\begin{array}{c}\text { MOI } \\
\text { R\$ }\end{array}$ & $\begin{array}{c}\text { Vol. } \\
\text { Produzido M }\end{array}$ & $\begin{array}{c}\text { Consumo } \\
\text { Massa } \\
\text { Tonelada }\end{array}$ \\
\hline 1 & 1.098 & 317.446 & 638.040 & 13.546 \\
\hline 2 & 1.003 & 337.564 & 580.392 & 11.991 \\
\hline 3 & 1.093 & 376.082 & 636.450 & 13.501 \\
\hline 4 & 1.058 & 343.009 & 645.397 & 13.339 \\
\hline 5 & 812 & 378.204 & 697.426 & 13.477 \\
\hline 6 & 1.039 & 339.418 & 587.669 & 12.549 \\
\hline 7 & 1.148 & 363.503 & 677.848 & 13.648 \\
\hline 8 & 1.145 & 368.342 & 704.689 & 13.781 \\
\hline 9 & 1.065 & 394.568 & 662.268 & 13.236 \\
\hline 10 & 1.102 & 316.342 & 693.303 & 13.954 \\
\hline 11 & 840 & 298.297 & 548.041 & 10.524 \\
\hline 12 & 469 & 306.002 & 548.041 & 10.524 \\
\hline
\end{tabular}

Fonte: Dados da pesquisa

Vale ressaltar que o valor destacado nos itens de custos indiretos referente ao gás natural está em (mil $\mathrm{m}^{3}$ ), e a $\mathrm{MOI}$ - mão-de-obra indireta está expressa em reais (moeda corrente nacional). Na coluna critério, o valor do volume produzido é elencado em $\left(m^{2}\right)$ e o consumo de massa em (Toneladas).

Os dados são reais e foram disponibilizados pelas gerências de custos das indústrias cerâmicas que estão sendo estudadas, sem nenhum indexador em qualquer item. Na seqüência, demonstra-se cada item de custo indireto e sua respectiva correlação com os critérios de rateio.

\subsection{Custos com mão-de-obra indireta}

$\mathrm{Na}$ tabela 5 são demonstrados os resultados finais dos cálculos de correlação elaborados no item de custo mão-de-obra indireta com os itens: volume produzido em $\mathrm{m}^{2}$ e consumo de massa em toneladas. Torna-se importante relatar que os gastos com gás para as indústrias cerâmicas representam, segundo informações obtidas no setor de custos, mais ou menos 35\% dos custos totais das empresas e 3\% são considerados MOI (mão-de-obra indireta). As correlações podem ser visualizadas na Tabela 5. 
Tabela 5 - Coeficientes de Correlação

\begin{tabular}{|c|c|c|}
\hline Empresas & $\begin{array}{c}\text { Vol. Produzido } \\
\mathbf{M}^{\mathbf{2}}\end{array}$ & $\begin{array}{c}\text { Consumo Massa } \\
\text { Ton. }\end{array}$ \\
\hline Alfa & 0,3239 & 0,3881 \\
\hline Beta & 0,2693 & 0,2364 \\
\hline Gama & 0,6280 & 0,6062 \\
\hline Média & 0,4071 & 0,4102 \\
\hline
\end{tabular}

Fonte: Dados da pesquisa

Observando-se os coeficientes expostos na Tabela 5, fica evidente a diferença de uma empresa para outra, e de um critério de rateio para outro.

$\mathrm{Na}$ empresa Alfa, com o emprego do "Consumo de Massa Toneladas", nota-se que o critério de rateio para o item de custo da "MOI" apresenta uma correlação positiva moderada, conforme pode ser visto na Tabela 5, chegando perto dos 39\% (pode-se melhor visualizar na figura 2).

Já, para a empresa Beta, o "Consumo de Massa Toneladas" apresenta um coeficiente de correlação próximo de $24 \%$, considerado como fraca correlação positiva, mesmo analisada pelo critério "volume produzido $\mathrm{m}^{2}$ ". É totalmente insignificante o aumento para mais ou menos $27 \%$, também considerada uma correlação positiva fraca.

As empresas em questão foram estudadas em função da semelhança, porte e acessibilidade, mas no final dos cálculos de correlação, houve surpresa nos resultados de cálculos encontrados na indústria Gama, sendo que esta apresentou o maior coeficiente de correlação, atingindo aproximadamente $63 \%$ com o "volume produzido em $\mathrm{m}^{2}$ ", revelando uma "Forte correlação positiva", em contraposição as outras duas indústrias analisadas, que apresentaram correlação positiva moderada e fraca correlação positiva. Sugere-se, então, buscar novos critérios de rateios, para possibilitar, assim, encontrar coeficientes mais favoráveis às indústrias em análise, principalmente nas empresas Alfa e Beta.

Conforme se verifica, ainda tomando por base a Tabela 5, o melhor critério de rateio é o "consumo de massa" com média geral de $41 \%$. Se a empresa Beta for retirada desta análise, a média geral sobe alguns pontos percentuais, passando para praticamente 50\%, o que, observado na Tabela 1 apresentada por Levin (2004), não é considerado um aumento relevante, mas tem-se neste momento uma correlação 
positiva.

As variáveis e seu comportamento são demonstradas nas Figuras 1 a 6 :

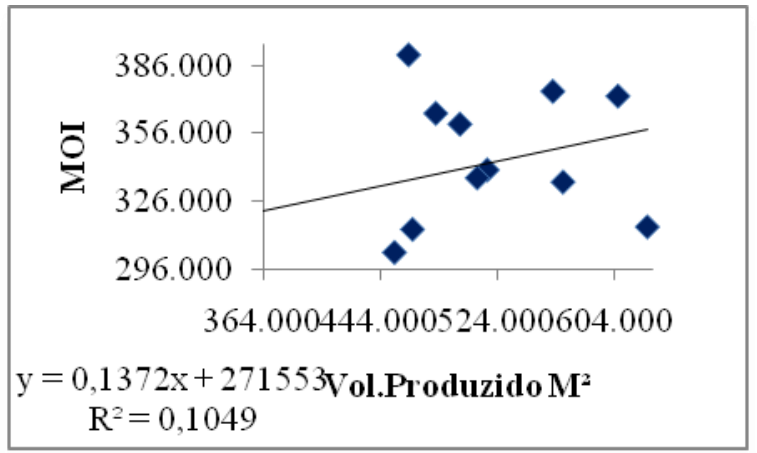

Figura 1 - Vol. Produzido $\mathrm{m}^{2}-$ Alfa

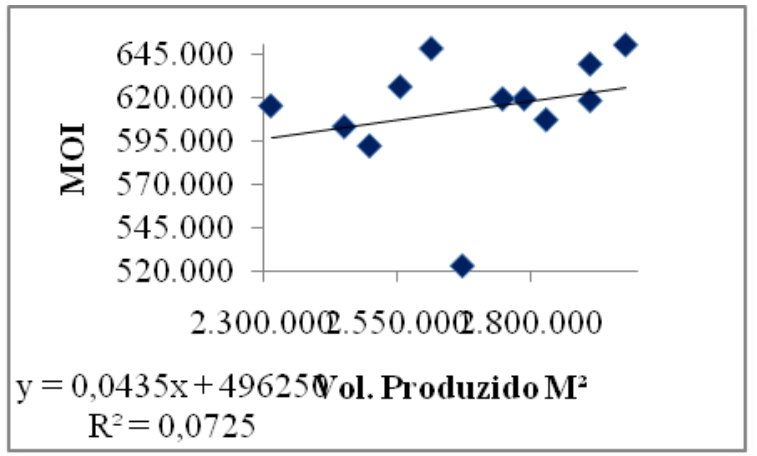

Figura 3 - Vol. Produzido $\mathrm{m}^{2}-$ Beta

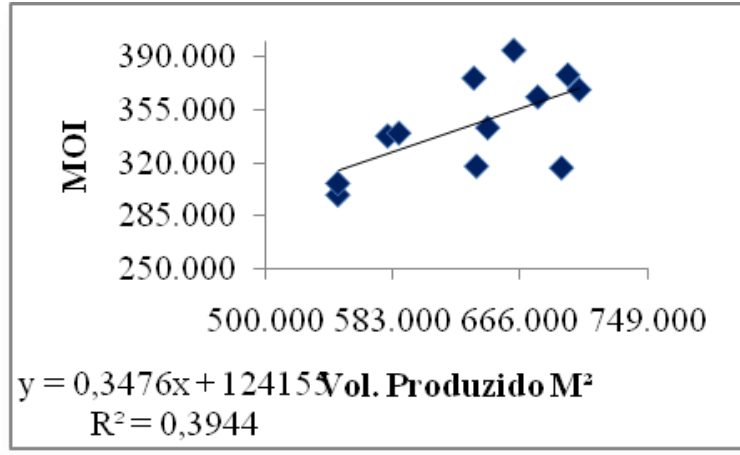

Figura 5 - Vol. Produzido $m^{2}$ - Gama

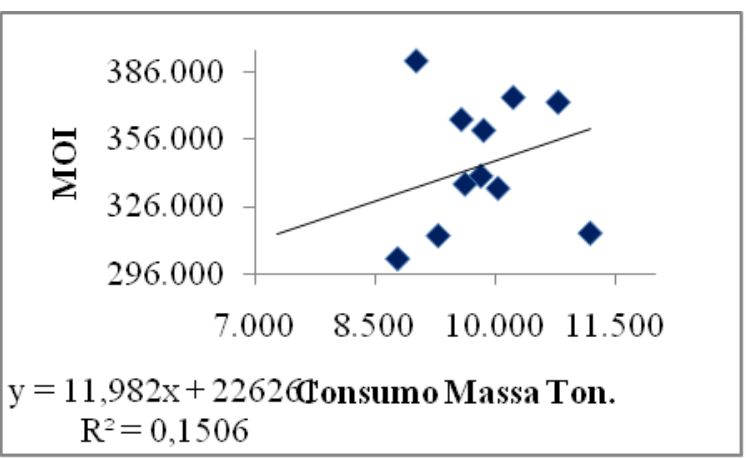

Figura 2 - Consumo Massa Ton. - Alfa

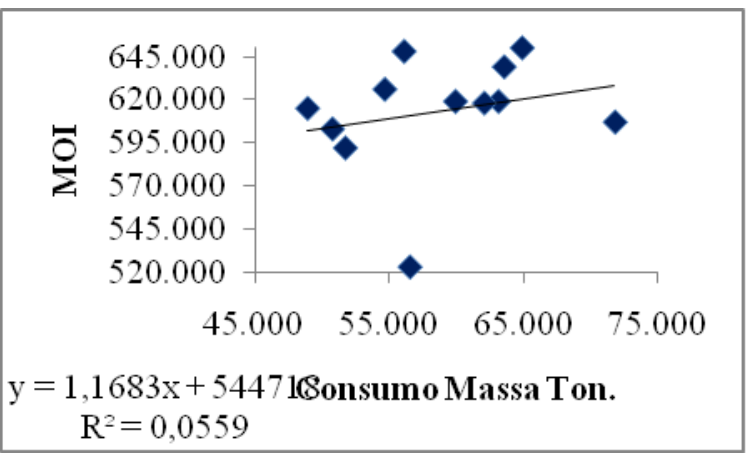

Figura 4 - Consumo Massa Ton. - Beta

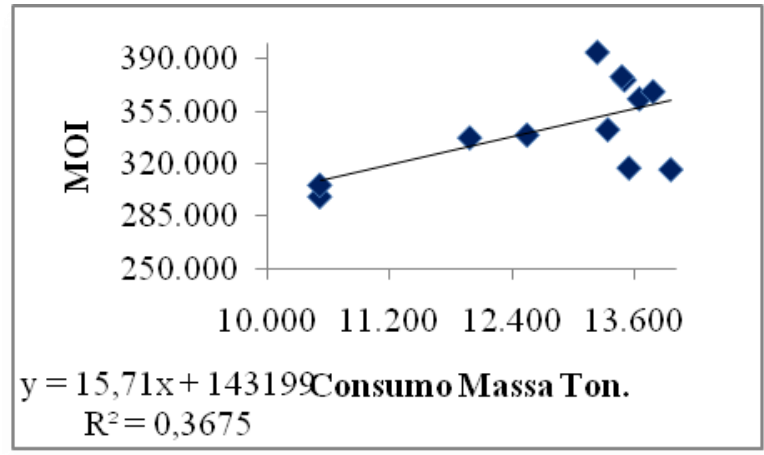

Figura 6 - Consumo Massa Ton. - Gama

Chega-se a conclusão que, apesar desta média ser muito baixa nas empresas Alfa e Beta, o emprego do "Consumo da Massa em toneladas" como critério de rateio para o item de custo "MOl" apresenta uma correlação "Moderada", com a média 
percentual de $41,02 \%$, como se observa na Tabela 5. Este coeficiente torna-se maior (55,64\%), caso seja retirado da análise o mês de janeiro das empresas Alfa e Beta e o mês de outubro da empresa Gama que apresenta certa discrepância em relação aos demais meses do ano, conforme demonstra a Tabela 6.

Mesmo sabendo que as empresas do estudo utilizam o consumo da massa como critério de rateio para o custo com a mão-de-obra indireta (MOI), verifica-se na Tabela 5 , que um "bom" critério de rateio para este item de custo é o valor do "volume produzido em $\mathrm{m}^{2 "}$ do período. Tal correlação atinge também um índice de $40,71 \%$, bem próximo dos $41 \%$.

Assim, se for excluído da análise o mês que apresenta discrepância no seu valor, obtém-se uma correlação média de aproximadamente 60,91\% (Tabela 6), o que já pode ser considerado como uma "forte" correlação entre o item de custo e o critério de rateio, representando até o momento a maior correlação. Os coeficientes de correlação podem ser observados na Tabela 6.

Tabela 6 - Coeficientes de Correlação

\begin{tabular}{|c|c|c|}
\hline Empresas & $\begin{array}{c}\text { Vol.Produzido } \\
\mathbf{M}^{\mathbf{2}}\end{array}$ & $\begin{array}{c}\text { Consumo Massa } \\
\text { Ton. }\end{array}$ \\
\hline Alfa & 0,5573 & 0,6253 \\
\hline Beta & 0,4738 & 0,2914 \\
\hline Gama & 0,7962 & 0,7524 \\
\hline Média & 0,6091 & 0,5564 \\
\hline
\end{tabular}

Fonte: Dados da pesquisa

Cabe ressaltar a importância dos métodos de custos, não somente na escolha do melhor critério de rateio, mas também acompanhar as variações dos custos de cada indústria cerâmica, como se pode observar na Tabela 6, onde a empresa Beta apresenta maior discrepância nos dados dos custos da "MOI". Observa-se, ainda, que o "volume produzido $\mathrm{m}^{2}$ ", mesmo após a eliminação do mês que comprometia seu resultado continua com $47,38 \%$, sendo considerada uma correlação positiva moderada. Para o "consumo da massa" tem-se o resultado de $29,14 \%$, considerado como fraca correlação positiva. 
Percebe-se a grande discrepância dos resultados encontrados na indústria Beta em relação às indústrias Alfa e Gama, que altera a correlação dos dados significativamente.

Eliminando-se a empresa Beta, tem-se outros resultados significantes, ou seja, a média geral das empresas Alfa e Gama se aproxima de 69\%, considerada, neste momento, como uma "forte correlação positiva".

As empresas Alfa e Gama, através do critério de rateio "volume produzido em $\mathrm{m}^{2}$ " atingem uma média total de $67,68 \%$ considerada como forte correlação positiva, isto acontece, também, no critério de rateio do "consumo da Massa", atingindo a escala dos $68,89 \%$, considerada "forte correlação positiva". Diante de níveis significativamente diferentes da empresa Beta em relação a Alfa e Gama, é importante uma ação investigativa para detectar perda ou sazonalidade, ou ainda identificar que se trata de uma situação de mero acaso.

\subsection{Custos com gás em $\mathrm{m}^{3}$}

O resultado dos cálculos de correlação dos testes realizados com os itens de custo "Gás em m" com o "volume produzido m" e o "Gás em m"3" com o "Consumo de Massa Toneladas", é apresentado na Tabela 7.

Tabela 7 - Coeficientes de Correlação

\begin{tabular}{|c|c|c|}
\hline Empresas & $\begin{array}{c}\text { Vol.Produzido } \\
\mathbf{M}^{\mathbf{2}}\end{array}$ & $\begin{array}{c}\text { Consumo Massa } \\
\text { Ton. }\end{array}$ \\
\hline Alfa & 0,7229 & 0,7945 \\
\hline Beta & 0,8211 & 0,6287 \\
\hline Gama & 0,5868 & 0,7763 \\
\hline Média & 0,7103 & 0,7332 \\
\hline
\end{tabular}

Fonte: Dados da pesquisa

$\mathrm{Na}$ empresa Alfa, que usa o "Consumo de Massa Toneladas", nota-se que o critério de rateio para o item de custo do "Gás em m ${ }^{3}$ " apresenta uma forte correlação positiva, estando próximo aos $80 \%$.

A empresa Beta, pelo critério de "Consumo de Massa Toneladas" apresenta o coeficiente de correlação de $63 \%$, que também é considerado forte correlação positiva, 


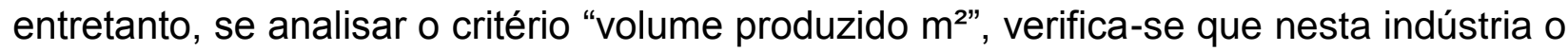
melhor critério de rateio é o "volume produzido $\mathrm{m}^{2}$ ", por apresentar um índice de correlação maior que $82 \%$, considerado "muito forte", sendo uma excelente escolha.

Já na empresa Gama, encontra-se o coeficiente de correlação próximo aos 59\%, referindo-se ao nível do "volume produzido em $\mathrm{m}^{2 "}$ ", considerado como "Correlação positiva moderada", sendo que a melhor escolha, atingindo o patamar de $78 \%$, é o critério de rateio pelo "consumo de massa em toneladas".

O comportamento dos custos indiretos, até aqui estudados, são demonstrados através de gráficos, para melhor visualização, nas figuras 7 a 12 .

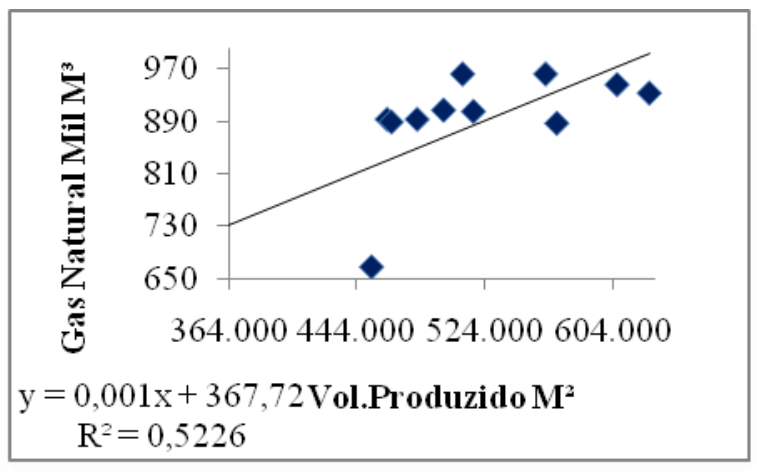

Figura 7 - Vol. Produzido $\mathrm{m}^{2}-$ Alfa

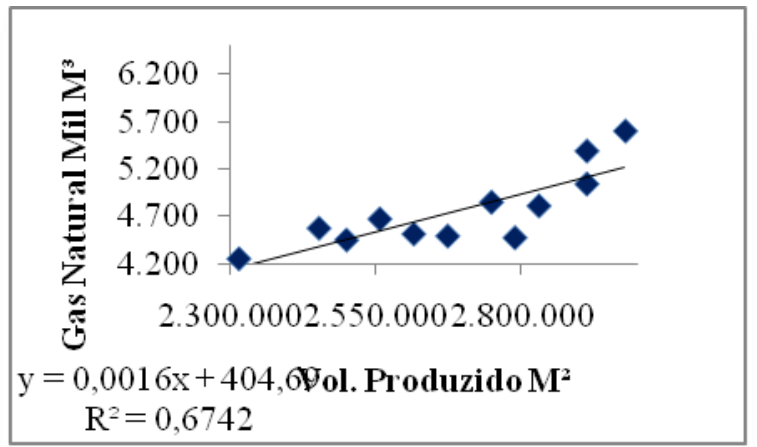

Figura 9 - Vol. Produzido $m^{2}-$ Beta

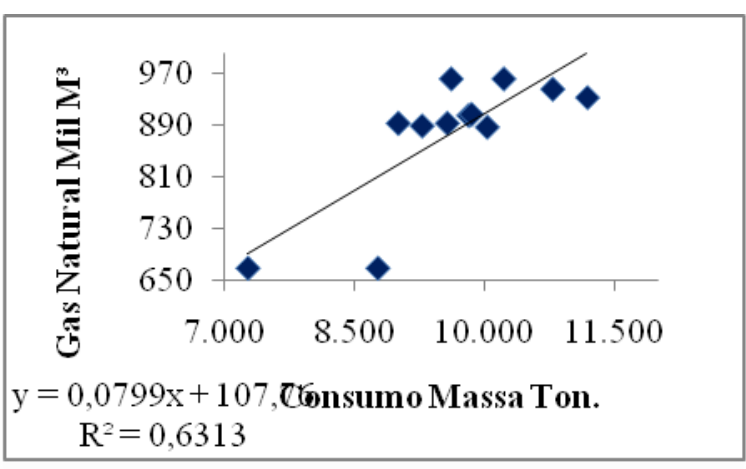

Figura 8 - Consumo Massa Ton. - Alfa

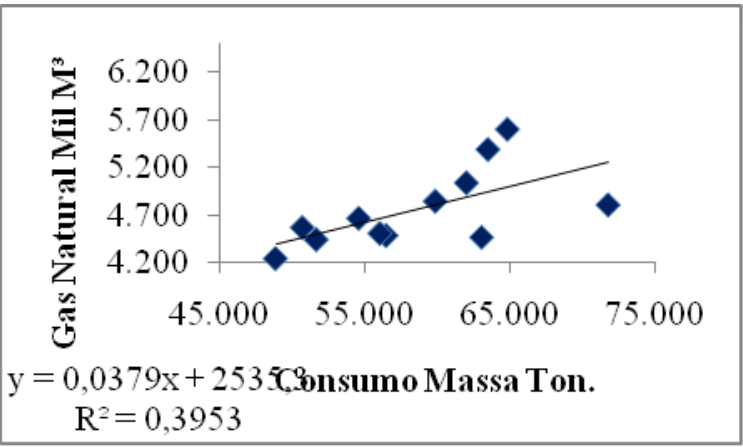

Figura 10 - Consumo Massa Ton. - Beta 


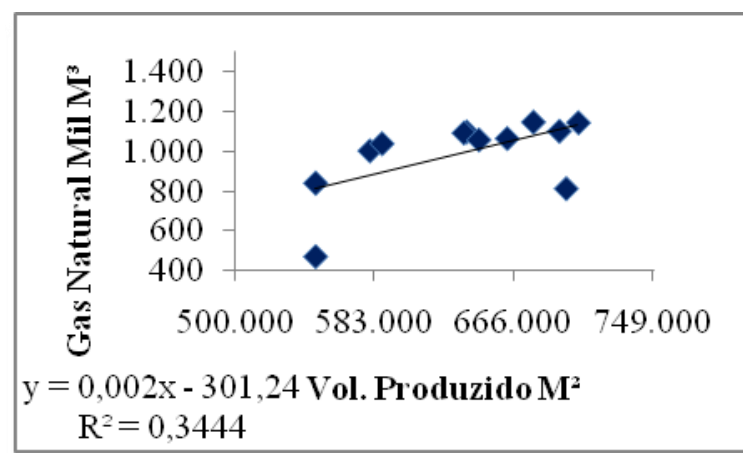

Figura 11 - Vol. Produzido $m^{2}$ - Gama

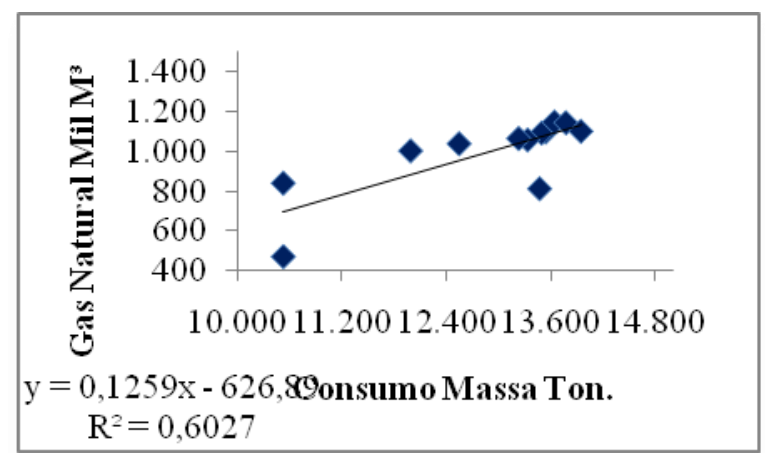

Figura 12 - Consumo Massa Ton. - Gama

Analisando-se a média aritmética dos coeficientes de correlação detectados nas três indústrias de cerâmicas (Tabela 7), verifica-se que o melhor critério de rateio é o "consumo de massa em toneladas", com o percentual próximo aos $74 \%$ em relação ao gás consumido durante o exercício em questão, chegando a uma correlação maior que $60 \%$, considerada positiva forte.

Neste caso, o emprego do "Consumo da Massa em toneladas" como critério de rateio para o item de custo "Gás Natural $\mathrm{m}^{3 "}$ apresenta uma correlação "Forte", com a média percentual de $73,32 \%$, como se observa na Tabela 7 . Este coeficiente torna-se maior (80,93\%), caso seja retirado da análise o mês de dezembro da empresa Alfa e o mês de maio das empresas Beta e Gama que apresentam certa discrepância em relação aos demais meses do ano, conforme demonstra a Tabela 8.

Tabela 8 - Coeficientes de Correlação

\begin{tabular}{|c|c|c|}
\hline Empresas & $\begin{array}{c}\text { Vol. Produzido } \\
\mathbf{M}^{\mathbf{2}}\end{array}$ & $\begin{array}{c}\text { Consumo Massa } \\
\text { Ton. }\end{array}$ \\
\hline Alfa & 0,7660 & 0,8488 \\
\hline Beta & 0,8864 & 0,7075 \\
\hline Gama & 0,7633 & 0,8715 \\
\hline Média & 0,8052 & 0,8093 \\
\hline
\end{tabular}

Fonte: Dados da pesquisa

Como já relatado no caso da $(\mathrm{MOI})$ as empresas utilizam o consumo da massa como critério de rateio para o custo do Gás Natural m³ ${ }^{3}$ então, verifica-se, pela Tabela 7 , que há um "bom" critério de rateio para este item de custo, o valor do "volume produzido 
em $\mathrm{m}^{2 "}$ do período. Tal correlação atinge também um índice de $71,03 \%$, considerada uma correlação excelente.

Assim, se for excluído da análise o mês que apresenta discrepância no seu valor, obtém-se uma correlação média de aproximadamente 80,52\% (Tabela 8), também considerada como uma "forte" correlação entre o item de custo e o critério de rateio, chegando bem próximo ao percentual encontrado no consumo da massa, classificado como "forte" podendo praticamente ser considerado como uma correlação positiva "perfeita".

\section{CONCLUSÃO}

A pesquisa teve por objetivo identificar os melhores critérios de apropriação dos custos indiretos nas três indústrias Cerâmicas do sul de Santa Catarina, mediante a utilização de técnicas estatísticas com o uso da análise de correlação e regressão. Em resumo, descreveu-se o método de custeio por absorção e informações importantes sobre o uso das técnicas estatísticas, bem como, alguns aspectos da contabilidade de custos e também como se deve analisar a correlação e regressão.

Com os testes efetuados, e com base nos resultados obtidos, as empresas devem, através do departamento de custos, analisarem qual o critério de rateio dos custos indiretos é mais aceitável na alocação aos produtos, tendo sempre como meta conseguir uma correlação maior que $50 \%$, ou seja, no mínimo a metade do custo deverá ser explicada por ele.

Apesar de o presente estudo apoiar-se em dados reais, o entendimento sobre 0 tema proposto foi de difícil interpretação. Contudo, para esclarecer sobre os melhores critérios de rateios dos itens de custo a serem utilizados em cada uma das empresas estudadas, fez-se a análise do melhor critério na alocação dos custos indiretos "Gás Natural" e "MOI". Considerou-se necessária a demonstração de outra tabela, com a finalidade de visualizar através de um resumo o melhor critério, bem como, os coeficientes alcançados com os dados das empresas Alfa, Beta e Gama (Tabela 9). 
Tabela 9 - Critérios de rateio e coeficientes de correlação

\begin{tabular}{|c|c|c|c|c|c|c|}
\hline \multirow{2}{*}{$\begin{array}{c}\text { Item de } \\
\text { Custo }\end{array}$} & \multicolumn{7}{|c|}{ Critério de Rateio } \\
\cline { 2 - 7 } & Alfa & Correlação & Beta & Correlação & Gama & Correlação \\
\hline Gás Natural & Massa & 0,7945 & Volume & 0,8211 & Massa & 0,7763 \\
\hline M.O.I & Massa & 0,3881 & Volume & 0,2693 & Volume & 0,6280 \\
\hline
\end{tabular}

Fonte: Dados da pesquisa

Nas indústrias em questão, os custos indiretos representam cerca de $38 \%$ dos custos totais de produção, fato este que evidencia a importância de se ter um método de rateio eficiente, pois a fórmula do sucesso ou do fracasso está na decisão de qual critério escolher.

O item custo indireto "MOl", segundo informações das empresas analisadas, corresponde a 3\% do total geral da produção, não sendo no momento preocupante, por se tratar de um baixo valor. O item "gás natural", todavia, corresponde a $35 \%$ do total geral da produção, tendo coeficientes de correlação bem superiores a $60 \%$, considerados até o momento como valores significativos e merecem uma atenção especial.

Desta forma, conclui-se que, pela análise de correlação e regressão da empresa Alfa e Gama, no que se refere ao custo "Gás Natural", é considerado de maior expressão, e deve continuar sendo usado como critério de rateio o "consumo da massa toneladas"; já a empresa Beta deverá rever sua sistemática no critério de "consumo da massa toneladas", pois através das técnicas estatísticas detectou-se que neste período de 2008 o melhor critério é o "volume produzido $\mathrm{m}^{2}$ ".

Em termos gerais, tomando por base as três empresas do setor cerâmico do sul de Santa Catarina estudadas, não se pode fazer qualquer tipo de generalização e/ou ampliar algum tipo de afirmação que inclua as demais empresas da região, sobretudo porque os resultados da pesquisa não apresentaram um padrão único de comportamento para os custos indiretos de produção, mesmo considerando-se as semelhanças existentes entre elas. 


\section{REFERÊNCIAS}

ATKINSON, Anthony A.; BANKER, Rajiv D.; KAPLAN, Robert S.; YOUNG, S. Mark. (2000). Contabilidade gerencial. São Paulo: Atlas, 812 p.

BISQUERRA, Rafael. (2004). Introdução à estatística: enfoque informático com o pacote estatístico SPSS. Porto Alegre: Artmed, $256 \mathrm{p}$.

LEONE, Jorge Sebastião Guerra. (2000). Curso de contabilidade de custos. (2 ed.). São Paulo: Atlas, $457 \mathrm{p}$.

LEVIN, Jack. FOX, James Alan. (2004). Estatística para ciências humanas. (9 ed.). São Paulo: Prentice Hall, $497 \mathrm{p}$.

MARTINS, Eliseu. (2008). Contabilidade de custos. (9 ed.). São Paulo: Atlas, 370 p.

STEVENSON, Willian J. (1981). Estatística aplicada à administração. São Paulo: Harper \& Row do Brasil, $495 \mathrm{p}$.

TRIOLA, Mario F. (2005). Introdução à estatística. (9 ed.). Rio de Janeiro: LTC, 656 p.

VICECONTI, Paulo Eduardo V.; NEVES, Silvério das. (2000). Contabilidade de custos: um enfoque direto e objetivo. São Paulo: Frase Editora, 248 p.

Data de Submissão:30/09/2010

Data de Aceite: 09/11/2011 